\title{
Human Health Risk Assessment of Trihalomethanes through Ingestion of Drinking Water in Shenzhen, China
}

\author{
Daokui Fang, Guohong Zhou*, Shuyuan Yu, Jinshu Feng, Yinsheng Guo \\ Institute of Environmental Health, Shenzhen Center for Disease Control and Prevention, Shenzhen, China \\ Email: *doczgh@sina.com
}

How to cite this paper: Fang, D.K., Zhou, G.H., Yu, S.Y., Feng, J.S. and Guo, Y.S. (2019) Human Health Risk Assessment of Trihalomethanes through Ingestion of Drinking Water in Shenzhen, China. Open Access Library Journal, 6: e5406.

https://doi.org/10.4236/oalib.1105406

Received: April 15, 2019

Accepted: May 5, 2019

Published: May 8, 2019

Copyright $\odot 2019$ by author(s) and Open Access Library Inc.

This work is licensed under the Creative Commons Attribution International License (CC BY 4.0).

http://creativecommons.org/licenses/by/4.0/

\begin{abstract}
The potential health hazards of trihalomethanes (THMs) contamination in drinking water in Shenzhen were estimated. The concentrations of THMs in drinking water from 13 centralized water supply systems were determined from Jan 2015 to Dec 2016 in Shenzhen. The water environmental health risk assessment model recommended by USEPA was established based on the water monitoring data of THMs. Preliminary health risks of THMs through ingestion of drinking water were assessed. The median concentrations of THMs, TCM, DBCM, BDCM and TBM in drinking water were 37.0, 24.5, 2.3, 7.8 and $0.3 \mu \mathrm{g} / \mathrm{L}$ respectively. The values of carcinogenic risks for THMs, TCM, DBCM, BDCM, and TBM to the individual per year in drinking water were $4.52 \times 10^{-5}, 2.38 \times 10^{-5}, 6.07 \times 10^{-6}, 1.52 \times 10^{-5}$ and $7.45 \times 10^{-8}$ respectively. The values of non-carcinogenic risks for THMs, TCM, DBCM, BDCM and TBM to the individual per year in drinking water were $9.32 \times 10^{-2}, 7.68 \times$ $10^{-2}, 3.61 \times 10^{-3}$, and $1.23 \times 10^{-2}$ and $4.71 \times 10^{-4}$ respectively. The health risk caused by THMs to the individual through ingestion of drinking water was in the order of TCM, BDCM, DBCM and TBM from high to low. The carcinogenic risks induced by THMs through ingestion of drinking water are acceptable with tolerable value offered by USEPA $\left(1.0 \times 10^{-6}-1.0 \times 10^{-4}\right)$, but reached to the tolerable value $\left(5.0 \times 10^{-5}\right)$ by International Commission on Radiological Protection (ICRP). The non-carcinogenic risk of THMs is tolerable $(\mathrm{HI}<1)$.
\end{abstract}

\author{
Subject Areas \\ Public Health \\ Keywords \\ Drinking Water, Trihalomethanes, Heath Risk Assessment
}




\section{Introduction}

Disinfection is indispensable for drinking water. Chlorine-based disinfectants are the most commonly applied products due to the versatility, effectiveness, low cost and residual disinfecting power of chlorine [1]. However, it is also known that the reactions between free chlorine and DBP precursors (e.g., natural organic matter, bromide ion) lead to the formation of disinfection by-products (DBPs) [2] [3]. In recent years, health risks of DBPs are of concern to people increasingly. Within these DBPs, the trihalomethanes (THMs), a class of carcinogenic organic halogenated by-product of water chlorination, have been recognized as potentially hazardous to human health and are the major by-products of chlorination [4]. THMs are formed due to the reactions between chlorine and the natural organic matter in water supplies, especially surface waters. Typically, the following four THMs are found as a result of chlorination: trichloromethane (TCM), bromodichloromethane (BDCM), dibromochloromethane (DBCM) and tribromomethane (TBM). These groups of compounds have been implicated in liver and kidney defects, central nervous system problems, cardiac arrhythmias and increased risk of carcinogenicity and mutagenicity as Class B carcinogens [5] [6] [7].

In the narrow sense, health risk assessment (HRA) was one of the key contents of environmental risk assessment emerging after the 1980s, which used risk as an evaluation index to link environmental pollution with human health and quantitatively described the risk of pollution to human health hazards. For the environmental health risk assessment procedures, the most common one is the four-step method published by the American Academy of Sciences in 1983 [8]. The health risk assessment of water environment is mainly for substances harmful to the human body in the water environment. These substances can be divided into two categories, gene toxic substances and somatic toxic substances. With the study on the hazard effects of harmful substances on human health through ingestion, risk models for health risks from carcinogens and non-carcinogens were established [9] [10] [11].

This study will mainly focus on the hazard studies on THMs in drinking water. In order to understand the sanitary status of drinking water quality and the health risks of THMs in Shenzhen, the concentrations of the chloroform, dibromomethane, dichloromonobromomethane and bromomethane in chlorinated water and tap water from municipal water supply plants in Shenzhen were tested and preliminary health risk assessment was performed according to the USEPA evaluation method.

\section{Materials and Methods}

\subsection{Sample Collection, Determination and Evaluation}

Drinking water samples from 13 centralized water supply systems from Jan 2015

to Dec 2016 in Shenzhen were collected, with a total of 52 factory samples and 16 peripheral samples. All filtered and acidified water samples were determined 
for TCM, DBCM, BDCM, and TBM using gas chromatography with electron capture detector (Table 1).

The test results were evaluated in accordance with GB 5749-2006 "Standards for Drinking Water Hygiene". The standard limits of TCM, DBCM, BDCM and TBM were $0.06,0.1,0.06,0.1 \mathrm{mg} / \mathrm{L}$ respectively. When the sum of the ratio of the concentrations of four disinfection by-products to the respective standard limits is less than 1, the THMs index is judged to be acceptable.

\subsection{Health Risk Model}

The International Agency for Research on International Cancer (IARC) usually divides the pollutants into two types: carcinogenic and non-carcinogenic. At the same time, the US Environmental Protection Agency (USEPA) establishes a risk model for health risk assessment based on whether the pollutants are carcinogenic. In general, carcinogenic pollutants have a non-carcinogenic health hazard effect.

\subsubsection{Health Risk Assessment of Non-Carcinogenic Pollutants}

Toxicological risks, expressed as the hazard index (HI), were calculated based on the comparison of the Lifetime Average Daily Dose (LADD) to the reference dose (RfD) as follows.

$$
\text { Hazard index for THMs of Oral Route }=\mathrm{LADD}_{\text {oral }} / \mathrm{RfD}
$$

where $\mathrm{RfD}$ is the reference dose for a specific substance, which is listed on USEPA Web site (USEPA, 2002).

where $\mathrm{LADD}_{\text {oral }}=($ total amount ingested/body weight $\times$ life time $)$

$$
=\left(\mathrm{C}_{\mathrm{W}} \times \mathrm{IR} \times \mathrm{EF} \times \mathrm{ED}\right) /(\mathrm{BW} \times \mathrm{AT})
$$

\subsubsection{Health Risk Assessment of Carcinogenic Pollutants}

In addition to toxic risks, carcinogenic risks of exposure to surveyed THM levels were calculated using the USEPA methodology. Carcinogenic compounds differ from toxic compounds in that there is no lower limit for the existence of risk. The LADD is typically used in conjunction with the Cancer Slope Factor (CSF) to calculate individual excess cancer risk. It is an estimate of the daily intake of a carcinogenic agent throughout the entire life of an individual. The CSF is the gradient of the line of the dose response curve derived from laboratory toxicological studies, and values for each substance are available in the USEPA IRIS

\begin{tabular}{|c|c|c|c|}
\hline Chemicals & Detection method & Equipment name & $\begin{array}{l}\text { Lowest detectable } \\
\text { limit (mg/L) }\end{array}$ \\
\hline TCM & \multirow{4}{*}{$\begin{array}{c}\text { Standard examination } \\
\text { method for drinking water } \\
\text { GB/T 5750.8-2006 }\end{array}$} & \multirow{4}{*}{$\begin{array}{l}\text { Gas chromatograph with } \\
\text { Electron capture detector }\end{array}$} & 0.06 \\
\hline DBCM & & & 0.1 \\
\hline $\mathrm{BDCM}$ & & & 0.06 \\
\hline TBM & & & 0.1 \\
\hline
\end{tabular}

Table 1. Detection parameters of THMs in drinking water. 
databases (USEPA, 2006). For THM species, the USEPA range of concern is for an increased carcinogenic risk of $10^{-6}$ i.e. 1:1,000,000 (USEPA, 2003). The following relationship was used to calculate the carcinogenic risks for THMs through ingestion [12].

$$
\text { THM carcinogenic risk of oral route }=\mathrm{LADD}_{\text {oral }} \times \mathrm{CSF}_{\text {oral }}
$$

The lifetime cancer risk for people living in area study was calculated using the input parameters in Table 2 and the THMs concentrations measured in this study. Table 3 summarizes the reference doses (RfD), cancer group classifications and cancer slope factors (CSF) for the THM components [13].

\subsection{Quality Control}

In order to ensure the quality of sampling and detection, parallel and blank controls are acquired simultaneously in each sampling. In the analysis process, a blank sample, a parallel sample and a spike recovery test are set up, and it is required that the component to be tested cannot be detected in the blank sample (the actual measurement result meets the requirements). Each batch of samples is tested with parallel quality control samples, and samples with too high or too low detection results are re-examined.

\subsection{Statistical Methods}

Excel 2007 was used for data entry and establishment of a water quality database. Statistical analysis was performed using SPSS 22.0 software. According to the

Table 2. Input parameters and abbreviations for exposure assessment.

\begin{tabular}{cccc}
\hline Input parameter & Units & Values & References \\
\hline THM Conc. in water $\left(C_{\mathrm{w}}\right)$ & $\mathrm{mg} / \mathrm{L}$ & See tables & Present study \\
Ingestion rate (IR) & L/day & 2.0 & USEPA (1997) \\
Exposure frequency (EF) & days/year & 365 & Lee et al. (2004) \\
Exposure duration (ED) & year & 70 & USEPA (1997) \\
Average exposure time (AT) & days/year & non-carcinogen: $30 \times 365$ & USEPA (2009) \\
Body weight (BW) & kg & 70 & Lee et al. (2004)
\end{tabular}

Table 3. Carcinogenic slope factors (CSF), reference doses (RfD) and cancer group classifications for THM components.

\begin{tabular}{cccc}
\hline Chemicals & Cancer group & $\mathrm{CSF}_{\text {oral }}(\mathrm{mg} / \mathrm{kg} / \mathrm{day})^{-1}$ & $\mathrm{RfD}(\mathrm{mg} / \mathrm{kg} /$ day $)$ \\
\hline Chloroform, $\mathrm{CHCl}_{3}$ & $\mathrm{~B} 1$ & $3.10 \mathrm{E}-02$ & $1.00 \mathrm{E}-02$ \\
Bromodichloromethane, $\mathrm{CHCl}_{2} \mathrm{Br}$ & $\mathrm{B} 2$ & $6.20 \mathrm{E}-02$ & $2.00 \mathrm{E}-02$ \\
Dibromochloromethane, $\mathrm{CHBr}_{2} \mathrm{Cl}$ & $\mathrm{C}$ & $8.40 \mathrm{E}-02$ & $2.00 \mathrm{E}-02$ \\
Bromoform, $\mathrm{CHBr}_{3}$ & $\mathrm{~B} 2$ & $7.90 \mathrm{E}-03$ & $2.00 \mathrm{E}-02$ \\
\hline
\end{tabular}

B1: probable human carcinogen with limited human data; B2: probable human carcinogen with sufficient animal data; C: possible human carcinogen. 
Kolmogorov-Smirnov normality test, the data of this study belonged to the non-normal distribution $(\mathrm{P}<0.01)$, so the median was used. The Mann-Whitney $\mathrm{U}$ test was used to compare the concentrations of disinfection by-products in the two groups. The Kruskal Wallis $\mathrm{H}$ multi-group rank sum test was used to compare the multiple groups and the exact probability was calculated. The difference was statistically significant at $\mathrm{P}<0.05$.

\section{Results}

\subsection{Detection of Disinfection By-Products in Water}

\subsubsection{Concentration of THMs in Different Types of Water Samples}

The concentrations (median) of TCM, DBCM, BDCM, TBM and THMs in drinking water in Shenzhen were 24.5, 2.3, 7.8, 0.3 and $37.0 \mu \mathrm{g} / \mathrm{L}$, respectively. A total of 68 water samples were tested, and there were 5 water samples with THMs exceeding the standard ( 3 pieces of factory water and 2 pieces of peripheral water). Among them, TCM in 2 pieces of water sample exceeded the standard ( 1 piece of the factory water and the peripheral water from different water plants). Comparing the qualified rate of THMs in the factory water [94.2\% $(49 / 52)]$ with that in the peripheral water [87.5\% (14/16)], the difference was not statistically significant (Table 4).

\subsubsection{The Concentration of THMs in the Water from Different Seasons} The THMs in the water samples of Shenzhen during the wet season (from April to October) and the dry season (from January to March, November and December) were all qualified. There was no significant difference in the concentrations of the four THMs components in the water samples during the wet and dry seasons (Table 5).

\subsubsection{Concentration of THMs in Factory Water from Different Water Plants}

The differences in the concentrations of four THMs in the water from different water plants were not statistically significant (Table 6).

\subsection{Health Risk Assessment of THMs through Ingestion of Drinking Water}

\subsubsection{Health Risks of THMs in Different Types of Water Samples}

The carcinogenic risk of THMs in drinking water in Shenzhen is $4.52 \times 10^{-5} / \mathrm{a}$, among which the carcinogenic risk of TCM is $2.38 \times 10^{-5} / \mathrm{a}$, accounting for $52.65 \%$

Table 4. Concentration of THMs in factory water and peripheral water in Shenzhen.

\begin{tabular}{ccccccc}
\hline \multirow{2}{*}{ Sample Type } & \multirow{2}{*}{$\begin{array}{c}\text { Sample } \\
\text { number }\end{array}$} & \multicolumn{5}{c}{ Average THMs level $(\mu \mathrm{g} / \mathrm{l})$ (median) } \\
\cline { 3 - 7 } & & TCM & DBCM & BDCM & TBM & THMs \\
\hline Factory Water & 52 & 23.6 & 2.3 & 7.8 & 0.3 & 35.7 \\
Peripheral Water & 16 & 30.3 & 2.3 & 7.8 & 0.3 & 39.3 \\
Total & 68 & 24.5 & 2.3 & 7.8 & 0.3 & 37.0 \\
\hline
\end{tabular}


Table 5. Concentration of THMs in factory water in different seasons in Shenzhen.

\begin{tabular}{ccccccc}
\hline \multirow{2}{*}{ Period } & \multirow{2}{*}{$\begin{array}{c}\text { Sample } \\
\text { Number }\end{array}$} & \multicolumn{5}{c}{ Average THMs level ( $\mu \mathrm{g} / \mathrm{l})$ (median) } \\
\cline { 3 - 7 } & 26 & 26.5 & DBCM & BDCM & TBM & THMs \\
\hline Wet Season & 2.9 & 8.4 & 0.3 & 37.1 \\
Dry Season & 26 & 21.4 & 2.1 & 7.4 & 0.3 & 32.7 \\
Total & 52 & 23.6 & 2.3 & 7.8 & 0.3 & 35.7 \\
\hline
\end{tabular}

Table 6. Concentration of THMs in factory water from 13 municipal water plants.

\begin{tabular}{cccccc}
\hline \multirow{2}{*}{$\begin{array}{c}\text { Water } \\
\text { Plant }\end{array}$} & \multicolumn{5}{c}{ Average THMs level $(\mathbf{n}=\mathbf{4}, \mu \mathrm{g} / \mathrm{l})$ (median) } \\
\hline plant1 & TCM & DBCM & BDCM & TBM & THMs \\
plant2 & 35.3 & 1.6 & 7.4 & 0.3 & 53.1 \\
plant3 & 26.8 & 4.5 & 11.9 & 0.3 & 48.2 \\
plant4 & 30.1 & 4.3 & 11.5 & 0.3 & 42.8 \\
plant5 & 24.9 & 2.1 & 6.7 & 0.3 & 39.4 \\
plant6 & 22.5 & 3.3 & 7.5 & 0.3 & 35.3 \\
plant7 & 22.7 & 1.4 & 9.5 & 0.3 & 35.5 \\
plant8 & 21.0 & 2.5 & 6.9 & 0.3 & 35.4 \\
plant9 & 23.9 & 2.1 & 8.0 & 0.3 & 34.5 \\
plant10 & 21.3 & 3.0 & 8.1 & 0.3 & 34.5 \\
plant11 & 19.4 & 1.9 & 8.6 & 0.3 & 33.1 \\
plant12 & 16.4 & 2.3 & 6.8 & 0.3 & 28.0 \\
plant13 & 15.0 & 1.7 & 7.5 & 0.3 & 26.8 \\
\hline
\end{tabular}

of THMs, which is the main carcinogenic risk substance. The hazard index of THMs is $9.32 \times 10^{-2} / \mathrm{a}$, among which the hazard index of TCM is $7.68 \times 10^{-2} / \mathrm{a}$, accounting for $82.40 \%$ of THMs. There was no significant difference in carcinogenic risk and health hazard index between the factory water and the peripheral water. The carcinogenic risk and health hazard index were in the order of TCM, BDCM, DBCM and TBM from high to low (Table 7).

\subsubsection{Health Risks of THMs of Factory Water in Different Seasons}

It can be seen from Table 8 that the average carcinogenic risk caused by THMs in different seasons through ingestion of drinking water is $4.43 \times 10^{-5} / \mathrm{a}$. The mean carcinogenic risk caused by TCM through ingestion of drinking water is $2.29 \times 10^{-5} / \mathrm{a}$, accounting for $51.69 \%$ of the carcinogenic risk of THMs. The hazard index of THMs through ingestion of drinking water in different seasons was $9.05 \times 10^{-2} / \mathrm{a}$. The average hazard index caused by TCM through ingestion of drinking water is $7.40 \times 10^{-2} / \mathrm{a}$, accounting for $81.86 \%$ of the THMs hazard index. There was no significant difference in health risks between the wet season and the dry season. The cancer risk and health hazard index were in the order of TCM, BDCM, DBCM, TBM from high to low. 
Table 7. Health risk assessment results of THMs in factory water and peripheral water in Shenzhen (/a).

\begin{tabular}{ccccc}
\hline & & Factory Water & Peripheral Water & Total \\
\hline & TCM & $7.40 \mathrm{E}-02$ & $9.52 \mathrm{E}-02$ & $7.68 \mathrm{E}-02$ \\
Hazard index & DBCM & $3.61 \mathrm{E}-03$ & $3.61 \mathrm{E}-03$ & $3.61 \mathrm{E}-03$ \\
& BDCM & $1.23 \mathrm{E}-02$ & $1.23 \mathrm{E}-02$ & $1.23 \mathrm{E}-02$ \\
& TBM & $4.71 \mathrm{E}-04$ & $4.71 \mathrm{E}-04$ & $4.71 \mathrm{E}-04$ \\
& Subtotal & $9.05 \mathrm{E}-02$ & $1.12 \mathrm{E}-01$ & $9.32 \mathrm{E}-02$ \\
& TCM & $2.29 \mathrm{E}-05$ & $2.95 \mathrm{E}-05$ & $2.38 \mathrm{E}-05$ \\
& DBCM & $6.07 \mathrm{E}-06$ & $6.07 \mathrm{E}-06$ & $6.07 \mathrm{E}-06$ \\
& BDCM & $1.52 \mathrm{E}-05$ & $1.52 \mathrm{E}-05$ & $1.52 \mathrm{E}-05$ \\
& TBM & $7.45 \mathrm{E}-08$ & $7.45 \mathrm{E}-08$ & $7.45 \mathrm{E}-08$ \\
& Subtotal & $4.43 \mathrm{E}-05$ & $5.09 \mathrm{E}-05$ & $4.52 \mathrm{E}-05$ \\
\hline
\end{tabular}

Table 8. Health risk assessment results of THMs in factory water in different seasons in Shenzhen City (/a).

\begin{tabular}{ccccc}
\hline & & Wet season & Dry season & Total \\
\hline \multirow{3}{*}{ Hazard index } & TCM & $8.31 \mathrm{E}-02$ & $6.71 \mathrm{E}-02$ & $7.40 \mathrm{E}-02$ \\
& DBCM & $4.48 \mathrm{E}-03$ & $3.22 \mathrm{E}-03$ & $3.61 \mathrm{E}-03$ \\
& BDCM & $1.32 \mathrm{E}-02$ & $1.16 \mathrm{E}-02$ & $1.23 \mathrm{E}-02$ \\
& TBM & $4.71 \mathrm{E}-04$ & $4.71 \mathrm{E}-04$ & $4.71 \mathrm{E}-04$ \\
Carcinogenic & Subtotal & $1.01 \mathrm{E}-01$ & $8.24 \mathrm{E}-01$ & $9.05 \mathrm{E}-02$ \\
risk & TCM & $2.58 \mathrm{E}-05$ & $2.08 \mathrm{E}-05$ & $2.29 \mathrm{E}-05$ \\
& BDCM & $7.52 \mathrm{E}-06$ & $5.41 \mathrm{E}-06$ & $6.07 \mathrm{E}-06$ \\
& TBM & $1.64 \mathrm{E}-05$ & $1.44 \mathrm{E}-05$ & $1.52 \mathrm{E}-05$ \\
& Subtotal & $7.45 \mathrm{E}-08$ & $7.45 \mathrm{E}-08$ & $7.45 \mathrm{E}-08$ \\
\hline
\end{tabular}

\subsubsection{Health Risk of THMs of Factory Water in Different Water Plants}

According to the health risk assessment model and parameters, the average individual annual risk caused by THMs in the water from the municipal water plants was calculated through oral route, as shown in Table 9. It can be seen from Table 9 that the carcinogenic risk of THMs through ingestion of drinking water is between $1.09 \times 10^{-6}-1.51 \times 10^{-4} / \mathrm{a}$, and the median is $4.43 \times 10^{-5} / \mathrm{a}$. The carcinogenic risk of TCM through ingestion of drinking water is between $9.74 \times 10^{-8}$ $-7.71 \times 10^{-5} / \mathrm{a}$, the median is $2.29 \times 10^{-5} / \mathrm{a}$, accounting for $51.69 \%$ of the total carcinogenic risk. The carcinogenic risk of other THMs is lower than that of TCM. The health hazard index of THMs through ingestion of drinking water is between $1.40 \times 10^{-3}-3.04 \times 10^{-1} / \mathrm{a}$, and the median is $9.05 \times 10^{-2} / \mathrm{a}$. The hazard index of TCM is in the range of $3.00 \times 10^{-4}-2.49 \times 10^{-1} / \mathrm{a}$, the median is $7.40 \times$ $10^{-2} / \mathrm{a}$, accounting for $81.77 \%$ of the total health hazard index. The health hazard indices of other THMs were lower than TCM. 
Table 9. Health risk assessment results of THMs in factory water of 13 municipal water plants in Shenzhen (/a).

\begin{tabular}{ccccc}
\hline \multirow{2}{*}{ THMs } & \multicolumn{2}{c}{ Hazard index } & \multicolumn{2}{c}{ carcinogenic risk } \\
\cline { 2 - 5 } & Range & Median & Range & Median \\
\hline TCM & $3.00 \mathrm{E}-04-2.49 \mathrm{E}-01$ & $7.40 \mathrm{E}-02$ & $9.74 \mathrm{E}-08-7.71 \mathrm{E}-05$ & $2.29 \mathrm{E}-05$ \\
DBCM & $3.00 \mathrm{E}-04-1.26 \mathrm{E}-02$ & $3.61 \mathrm{E}-03$ & $5.28 \mathrm{E}-07-2.11 \mathrm{E}-05$ & $6.07 \mathrm{E}-06$ \\
BDCM & $3.00 \mathrm{E}-04-4.24 \mathrm{E}-02$ & $1.23 \mathrm{E}-02$ & $3.90 \mathrm{E}-07-5.26 \mathrm{E}-05$ & $1.52 \mathrm{E}-05$ \\
TBM & $4.71 \mathrm{E}-04-4.71 \mathrm{E}-04$ & $4.71 \mathrm{E}-04$ & $7.45 \mathrm{E}-08-7.45 \mathrm{E}-08$ & $7.45 \mathrm{E}-08$ \\
Total & $1.40 \mathrm{E}-03-3.04 \mathrm{E}-01$ & $9.05 \mathrm{E}-02$ & $1.09 \mathrm{E}-06-1.51 \mathrm{E}-04$ & $4.43 \mathrm{E}-05$ \\
\hline
\end{tabular}

\section{Discussions}

From the concentration of drinking water DBPs in some cities in China reported by Deng et al. [14], the concentration of THMs in municipal waters in Shenzhen is at a medium level. Compared with other test results in Shenzhen, the concentration of THMs (excluding TBM) is significantly higher. This may be related to the year of the test and the location of the water plant, suggesting that attention should be paid to the differences in water quality in different regions. This study found that the concentration of THMs in 5 water samples exceeded the standard. It is recommended that the water supply unit should analyze the cause of excessive THMs concentration to reduce the THMs concentration.

The results of this study indicated that the annual carcinogenic risk caused by THMs in some water plants in Shenzhen was between $3.07 \times 10^{-5}$ and $6.81 \times$ $10^{-5} / \mathrm{a}$, with a mean value of $4.43 \times 10^{-5} / \mathrm{a}$. Among them, the carcinogenic risk caused by TCM through ingestion of drinking water was in the range of $1.46 \times$ $10^{-5}-4.41 \times 10^{-5} / \mathrm{a}$, and the mean value is $2.29 \times 10^{-5} / \mathrm{a}$, which was the main source of THMs carcinogenic risk. The carcinogenic risk of THMs was in the order of TCM, BDCM, DBCM, and TBM from high to low, which accounted for $51.69 \%, 34.31 \%, 13.70 \%$, and $0.17 \%$ of the total carcinogenic risk of THMs respectively.

USEPA's acceptable risk level for carcinogens is between $1.0 \times 10^{-6}-1.0 \times$ $10^{-4} / \mathrm{a}$ [9] [15], $<1.0 \times 10^{-6} / \mathrm{a}$ represents that the risk is not obvious, $1.0 \times 10^{-6}$ $1.0 \times 10^{-4} / \mathrm{a}$ indicates there is a risk but is acceptable, $>1.0 \times 10^{-4} / \mathrm{a}$ indicates there is a significant risk. The maximum acceptable risk level recommended by the International Commission on Radiation Protection (ICRP) is $5.0 \times 10^{-5} / \mathrm{a}$, which is currently not available in China.

The average carcinogenic risk of THMs through ingestion of drinking water in Shenzhen municipal drinking water was within the acceptable risk of USEPA, but there was still a health risk. Although the mean carcinogenic risk was still below the maximum acceptable value recommended by ICRP, it was close to an acceptable threshold. In addition, there were 3 water plants with carcinogenic risk values exceeding the critical value, and 1 close to critical value. It should be of sufficient concern. In accordance with USEPA's risk control requirements, 
with a risk value of $1.0 \times 10^{-6} / \mathrm{a}$, a feasible risk management strategy should be proposed. The author's previous research showed that the health risks of heavy metals in drinking water sources in the region reached the maximum acceptable value recommended by the ICRP (IV). Therefore, it is necessary to conduct a comprehensive health risk assessment of local drinking water.

The hazard index of THMs through ingestion of drinking water in different water plants is $1.40 \times 10^{-3}-3.04 \times 10^{-3} / \mathrm{a}$, with an average of $9.05 \times 10^{-2} / \mathrm{a}$. The hazard index of TCM through ingestion route is in the range of $3.00 \times 10^{-4}-2.49$ $\times 10^{-1} / \mathrm{a}$, the average value is $7.40 \times 10^{-2} / \mathrm{a}$, the health hazard index is in the order of TCM, BDCM, DBCM, TBM from high to low. They accounted for $81.77 \%$, $13.59 \%, 3.99 \%$, and $0.52 \%$ of the hazard index respectively.

The average health hazard index produced by THMs through ingestion of drinking water was less than 1 , and health indicators of 13 water plants were all below 1 . It is expected that it will not cause health damage and meet safety requirements.

Because the water environment health risk assessment system involves many uncertain factors, such as the distribution of pollutants concentration, the exposure level, and the risk tolerance level of different groups of people. All these factors make the evaluation results uncertain to some extent.

This study adopted the USEPA drinking water THMs risk assessment method for human health exposure. For the exposure route, only the average drinking water intake was considered without other exposure pathways. Due to the low boiling point of THMs, except for oral exposure, it also includes skin contact, respiratory vapor inhalation, etc., which actually underestimates the risk of THMs exposure. Shenzhen is located in the south of China. Bathing and swimming are common and the frequency of exposure is high. The carcinogenic risk caused by these pathways cannot be ignored.

Due to the uncertainty of health risk assessment itself, there are no standard exposure parameters for health risk assessment in China. Therefore, the USEPA data is often cited in terms of life expectancy, body weight, water intake and carcinogenic slope factors, choice of reference dose, and cumulative effects of toxic substances on human health hazards. Due to differences in ethnicity and living habits, the parameters are not completely suitable for Chinese residents. According to EPA parameters, there is a certain deviation in the evaluation results. Therefore, the research on the exposure risk of THMs in drinking water in Shenzhen needs further study.

We wish to express our gratitude to the 'Research Base for Environment and Health in Shenzhen Center for Disease Control and Prevention, Chinese Center for Disease Control and Prevention' and the participants for their cooperation in this study.

\section{Conflicts of Interest}

The authors declare no conflicts of interest regarding the publication of this paper. 


\section{References}

[1] Pándics, T., Hofer, Á., Dura, G., et al. (2018) Health Risk of Swimming Pool Disinfection By-Products: A Regulatory Perspective. Journal of Water and Health, 16, 947-957. https://doi.org/10.2166/wh.2018.178

[2] Chang, E.E., Chiang, P.C., Ko, Y.W., et al. (2001) Characteristics of Organic Precursors and Their Relationship with Disinfection By-Products. Chemosphere, 44, 1231-1236. https://doi.org/10.1016/S0045-6535(00)00499-9

[3] Tak, S. and Vellanki, B.P. (2018) Natural Organic Matter as Precursor to Disinfection Byproducts and Its Removal Using Conventional and Advanced Processes: State of the Art Review. Journal of Water and Health, 16, 681-703. https://doi.org/10.2166/wh.2018.032

[4] Nieuwenhuijsen, M.J., Smith, R., Golfinopoulos, S., et al. (2009) Health Impacts of Long-Term Exposure to Disinfection By-Products in Drinking Water in Europe: HIWATE. Journal of Water and Health, 7, 185-207. https://doi.org/10.2166/wh.2009.073

[5] Sridhar, N., Krishnakishore, C., Sandeep, Y., et al. (2011) Chloroform Poisoning-A Case Report. Renal Failure, 33, 1037-1039. https://doi.org/10.3109/0886022X.2011.618920

[6] Richardson, S.D., Plewa, M.J., Wagner, E.D., et al. (2007) Occurrence, Genotoxicity, and Carcinogenicity of Regulated and Emerging Disinfection By-Products in Drinking Water: A Review and Roadmap for Research. Mutation Research, 636, 178-242. https://doi.org/10.1016/j.mrrev.2007.09.001

[7] Chowdhury, S., Rodriguez, M.J., Sadiq, R., et al. (2011) Disinfection Byproducts in Canadian Provinces: Associated Cancer Risks and Medical Expenses. Journal of Hazardous Materials, 187, 574-584. https://doi.org/10.1016/j.jhazmat.2011.01.085

[8] Goldstein, B.D. (2005) Advances in Risk Assessment and Communication. Annual Review of Public Health, 26, 141-163.

https://doi.org/10.1146/annurev.publhealth.26.021304.144410

[9] USEPA (2005) Guidelines for Carcinogen Risk Assessment. EPM603/P-03/001F, Washington DC.

[10] USEPA (2011) Exposure Factors Handbook: 2011 Edition. EPA/600/R-09/052F, Washington DC.

[11] USEPA (1991) Risk Assessment Guidance for Superfund Volume I-Human Health Evaluation Manual (Part B, Development of Risk Based Preliminary Remediation Goals). EPA/540/R92/003, Washington DC.

[12] Karim, Z., Qureshi, B., Ghouri, I., et al. (2013) Spatial Analysis of Human Health Risk Associated with Trihalomethanes in Drinking Water: A Case Study of Karachi, Pakistan. Journal of Chemistry, 2013, Article ID: 805682. https://doi.org/10.1155/2013/805682

[13] RAIS (Risk Assessment Information System) (2009) USEPA (Electronic Data Base). http://rais.ornl.gov

[14] Deng, Y., Wei, J., et al. (2008) Study for Distribution Level of Disinfection Byproducts in Drinking Water from Six Cities in China. Journal of Hygiene Research, 37, 207-210.

[15] Office of Water USEPA (2012) Edition of the Drinking Water Standard and Health Advisories. EPA 822-S-12-001, Washington DC. 